\title{
ChILE 2020: PANDEMIA Y PLEBISCITO CONSTITUCIONAL*
}

Chile 2020: Pandemic and Constitutional Plebiscite

\section{CARLOS MELÉNDEZ}

Universidad Diego Portales, Chile

\section{CRISTÓBAL ROVIRA KALTWASSER}

Universidad Diego Portales, Chile

\section{JAVIER SAJURIA}

Queen Mary University of London, Reino Unido

\begin{abstract}
RESUMEN
Dos son los hitos más importantes que marcaron la política chilena durante el año 2020: la pandemia y el plebiscito constitucional. Mientras el primer fenómeno era absolutamente inesperado e implicó un giro importante en la agenda política del país, el segundo era bastante probable que terminara en un triunfo de la opción a favor del cambio constitucional, pero la contundencia del resultado fue sorpresiva. En este artículo analizamos ambos hitos en detalle. Por un lado, examinamos cómo el gobierno en particular, y el sistema político en general, reaccionaron frente a la irrupción y el desarrollo de la pandemia. Por otro lado, basándonos en una encuesta cara a cara representativa de la población - que se llevó a cabo justo después del plebiscito - mostramos empíricamente que el voto "Rechazo" se explica en gran medida por las variables que en estudios comparados se utilizan para predecir apoyo a fuerzas de derecha populista radical, mientras que el voto "Apruebo" se caracteriza por una alta heterogeneidad en términos ideológicos y sociológicos. En resumen, la evidencia aquí presentada refuerza los hallazgos de otras investigaciones que muestran un aumento de las tensiones al interior del bloque de centroderecha y, a su vez, permite pensar que en Chile están dadas las condiciones para que se establezca una fuerza de derecha populista radical.
\end{abstract}

Palabras Clave: derecha, populismo, plebiscito, proceso constituyente, Covid-19.

\footnotetext{
Los autores quisieran agradecer la ayuda de Ariel Becerra en la recopilación de algunos de los datos que figuran en este artículo y también los valiosos comentarios de tres evaluadores externos. A su vez, Cristóbal Rovira Kaltwasser agradece el apoyo del Fondo Nacional de Desarrollo Científico y Tecnológico de Chile (proyecto Fondecyt 1180020), del Centro de Estudios de Conflicto y Cohesión Social (COES, ANID/ Fondap /15130009) y del Observatorio de Transformaciones Socioeconómicas (ANID/PCI/Max Planck Institute for the Study of Societies /MPG190012). Por su parte, Carlos Meléndez agradece el apoyo del Centro de Estudios de Conflicto y Cohesión Social (COES, ANID/Fondap/15130009).
} 


\begin{abstract}
There are two milestones that marked Chilean politics during 2020: the COVID-19 pandemic, and the constitutional plebiscite. While the former was an absolutely unexpected phenomenon that forced an important turn in the country's political agenda, the result of latter was foreseeable yet surprising. In fact, the plebiscite was likely to end in a triumph of the option in favour of constitutional change, but the forcefulness of the result was surprising. In this article we look at both milestones in detail. On the one hand, we examine how the government in particular, and the political system in general, reacted to the emergence and development of the pandemic. On the other hand, based on a representative face-to-face survey of the population - which was carried out just after the plebiscite - we empirically show that the "Reject" vote is largely explained by the factors used in comparative studies to predict support for populist radical right (PRR) forces, while the "Approve" vote is characterized by high heterogeneity in ideological and sociological terms. In summary, the evidence presented here reinforces previous findings that show an increase in tensions within the centre-right bloc and, in turn, suggests that in Chile the conditions are ripe for the establishment of a populist radical right force.
\end{abstract}

Keywords: right, populism, plebiscite, constituent process, Covid-19.

\title{
I. INTRODUCCIÓN
}

A inicios del año 2020, la situación política de Chile venía recuperando cierta normalidad luego del estallido social de fines del 2019. Este último trajo consigo una serie de tensiones para el sistema político. Por un lado, como consecuencia del estallido social comenzó a aflorar una fuerte rivalidad al interior de la centroderecha, ya que ciertos sectores pujan por una moderación programática y acercamiento hacia el centro político, mientras que otros sectores intentan más bien una radicalización programática y aproximamiento hacia lo que la literatura en política comparada llama la "derecha populista radical" (Rovira Kaltwasser 2019, 2020) ${ }^{1}$. Si bien es cierto que las tensiones ideológicas y programáticas no son nuevas al interior de la derecha chilena (Alenda, Le Foulon y Súarez-Cao 2019; Alenda 2020; Alenda, Suárez-Cao y Le Foulon 2020), la rivalidad interna ha venido cobrando particular virulencia últimamente y esto ciertamente ha dificultado la capacidad de la administración de Sebastián Piñera para mantener a su coalición ordenada y conseguir niveles de aprobación ciudadana aceptables.

Por otro lado, el estallido social no ayudó precisamente a mejorar las relaciones entre las distintas fuerzas de centroizquierda, sino que más bien exacerbó va-

\footnotetext{
La literatura académica plantea que la derecha populista radical es un fenómeno global que, pese a ciertas diferencias a nivel nacional, se caracteriza por articular tres atributos ideológicos: autoritarismo, nativismo y populismo (Mudde 2007; Mudde y Rovira Kaltwasser 2018). En primer lugar, el autoritarismo consiste en la defensa de una imagen jerárquica de la sociedad, la cual ataca con dureza las "conductas desviadas". En segundo lugar, el nativismo debe ser entendido como una suerte de nacionalismo chauvinista, ya que plantea que el Estado debe ser habitado exclusivamente por la población "nativa" y que tanto ideas como personas "no nativas" son consideradas como una amenaza para la comunidad política. Por último, el populismo es una ideología política basada en la distinción entre una elite corrupta versus un pueblo puro y que defiende a como dé lugar la soberanía popular (Mudde y Rovira Kaltwasser 2017).
} 
rias de las disputas que existen entre ellas (v.gr. Peña 2020 en contraposición a Ruíz Encina 2020). En efecto, surgieron serias discrepancias al interior de este campo al momento de evaluar no solo las causas y consecuencias del estallido social, sino que también respecto a legitimar o no el uso de la fuerza por parte de quienes protestan y de las fuerzas de seguridad. Al igual que sucede con el espacio de centroderecha, la centroizquierda apareció durante el año 2020 muy dividida entre grupos que mantienen disputas generacionales, programáticas y de liderazgo, sin mostrar atisbos de una posible alianza implícita o explícita entre ellos con el afán de lograr una mayoría electoral. En resumen, el Chile "post estallido social" se caracteriza por elevados niveles de fragmentación a nivel de élites políticas, azuzados por discrepancias notables al interior de cada campo ideológico.

En consecuencia, la expectativa era que el año 2020 iba a estar marcado por un plebiscito constitucional, en donde se verían las crecientes tensiones al interior del bloque de centroderecha y la prolongación de las existentes pugnas al interior del bloque de centroizquierda. Aún cuando este diagnóstico es válido, la irrupción de la pandemia del coronavirus operó como un verdadero shock externo que rápidamente modificó la agenda y el debate político. La llegada del virus causante del COVID19 implicó una constante preocupación por el sistema de salud del país y su potencial colapso, así como también una severa crisis económica relacionada con la implementación de políticas de confinamiento. A su vez, el plebiscito constitucional que inicialmente estaba programado para el mes de abril de 2020 fue pospuesto para el mes de octubre del mismo año, una medida que fue apoyada por el conjunto de la clase política para evitar que este proceso eleccionario fuese llevado a cabo en pleno periodo de expansión del virus y de confinamiento de gran parte de la población del país.

La pandemia afectó seriamente el funcionamiento del sistema político. Los conflictos que llevaron a la irrupción del estallido social de fines del año 2019 (Somma et al. 2020) y las demandas expuestas en la esfera pública - como por ejemplo de los movimientos feminista (Reyes-Housholder y Roque 2019) y estudiantil (Palacios-Valladares 2020) - no se difuminaron pero sí sufrieron cambios. El movimiento feminista continuó gravitando en la definición de la agenda pública, especialmente en el debate constitucional, permitiendo así la gestación de la Ley 21.216 sobre "Paridad de Género para el Proceso Constituyente" (Freidenberg y Suárez Cao 2021). Si bien la crisis sanitaria llevó a una desmovilización forzada de las protestas y descomprimió temporalmente la crisis social que se arrastraba desde octubre del 2019, el gobierno continuó padeciendo de serios problemas de legitimidad social. Los conflictos sociales se retiraron un tanto de la agenda mediática, aunque sus causas (como la desigualdad o la precariedad del sistema laboral) se vieron exacerbadas por la pandemia.

De hecho, tanto el estallido social como la pandemia condujeron a poner como elemento central de discusión pública la desigualdad y la precarización de las clases medias en el país (Heiss 2020) y se evidenció la incapacidad del gobierno 
en reaccionar frente a estos factores estructurales más allá de medidas cortoplacistas (Castiglioni 2020a). Tanto desde gobiernos locales (alcaldes empáticos con las urgencias de sus vecinos en el contexto pandémico) como desde el Congreso (legisladores de diverso color político apoyaron el retiro anticipado de los ahorros previsionales, como veremos más adelante), se desafió aún más la legitimidad de la administración de turno. El gobierno de Piñera perdió control sobre los parlamentarios de su sector en votaciones claves porque la emergencia de la pandemia debilitó un sistema de "incentivos a la disciplina y castigos a la indisciplina" con el que había funcionado el "cartel legislativo" (Toro y Valenzuela 2020). Así, algunos bautizaron, de forma errónea, a estas acciones como un "parlamentarización de facto"; y la toma de decisiones de más alto nivel puso en discusión también la vigencia de la forma de gobierno presidencialista (e.g. Fontaine 2021). Y asimismo el gabinete de ministros vio lesionada su estabilidad. Durante el 2020, se produjeron dieciseís cambios ministeriales ${ }^{2}$ que evidenciaron el mal llevar de la alianza de gobierno con serias dificultades para controlar la agenda pública.

Para comprender las consecuencias del estallido social y de la pandemia del COVID19 en la crisis de representación política, el presente artículo se divide en tres apartados. En primer lugar, comenzamos ofreciendo un análisis sobre la irrupción de la pandemia, su manejo por parte del gobierno y la presión ejercida por la oposición para demandar medidas económicas que ayuden a quienes se vieron más afectados. En segundo lugar, nos detenemos en analizar los resultados el plebiscito constitucional de octubre del 2020 y para ello utilizamos evidencia empírica de una encuesta cara a cara representativa de la población que se llevó a cabo durante los meses de noviembre y diciembre de ese año. En tercer y último lugar, presentamos una breve conclusión que resume los argumentos centrales del artículo y además plantea algunas ideas respecto a cómo el resultado del plebiscito constitucional nos da pistas para pensar el Chile que comienza a surgir a partir del proceso constitucional en ciernes. En la organización de este recuento anual, hacemos notar hallazgos específicos sobre el campo político de la derecha, no solo por tratarse de la coalición de poder que sustenta al gobierno de Sebastián Piñera (a cargo de reaccionar frente a los desafíos de la pandemia) sino porque además, a través del análisis del voto por el "rechazo", podemos evidenciar giros relevantes en la demanda electoral correspondiente a este sector.

\footnotetext{
Marcela Cubillos renunció a Educación el 28 de febrero del 2020, Isabel Plá dejó el ministerio de la Mujer y la Equidad de Género el 13 de marzo del 2020 y Macarena Santelices asumió la misma cartera el 6 de mayo del 2020. El 4 de junio del 2020, Piñera anunció tres cambios ministeriales (Desarrollo Social, Secretaría General de la Presidencia y Vivienda y Urbanismo) y cinco días después volvió a hacer un cambio en el sector Mujer y Equidad de Género. El 13 de junio se realizó el cambio en Salud: Enrique Paris por Jaime Mañalich. El 28 de julio se realizó el cambio en un total de 6 ministerios, incluyendo el ingreso al gabinete de figuras de la derecha como Andrés Allamand en Cancillería y Mario Desbordes en Defensa. Este último renunció el 18 de diciembre en miras de su eventual candidatura presidencial, propiciando el último cambio ministerial del año.
} 


\section{LA PANDEMIA DEL COVID-19}

Enero y febrero son meses en que, tradicionalmente, la política chilena entra en pausa producto de las vacaciones de verano. Marzo es entonces el mes en que se inicia el quehacer político, el cual usualmente parte el 8 de marzo, Día Internacional de la Mujer. En 2020, esto implicó una masiva marcha del movimiento feminista a lo largo del país. Todo indicaba, entonces, que este sería un nuevo año marcado por los ciclos de movilizaciones y protestas que el país ha venido experimentando en el último tiempo (Donoso y von Bülow 2017). Sin embargo, a medida que avanzaba este mes, cada vez ganaba más espacio el COVID19 en las noticias y el debate político. Por tanto, el Ministro de Salud de ese entonces, Jaime Mañalich, comenzó a acaparar gran importancia. Mañalich es médico, sin afiliación partidaria, amigo del Presidente Piñera y, por lo mismo, contaba con su absoluta confianza. Desde un comienzo, el Ministro de Salud aseguró que el sistema de salud del país estaba preparado para enfrentar la pandemia, de modo que no iba a suceder "una tragedia como en Italia o España" (El Mercurio 2020). Sin embargo, la realidad terminó siendo bastante distinta a la profesada por dicho responsable sectorial.

El gobierno de Piñera no adoptó rápidamente medidas de confinamiento para tratar de detener la dispersión del virus, aun cuando una gran cantidad de expertos hicieron esta recomendación ${ }^{3}$. Recién el 15 de mayo (75 días después de que se conociera el primer caso de COVID19 en el país) el gobierno implementó el confinamiento de la capital del país, Santiago, y esta medida se mantuvo en pie por más de tres meses en la gran mayoría de las comunas de la ciudad. Producto de la tardía implementación del confinamiento y serios problemas para instalar un sistema eficiente de trazabilidad, la primera ola de la pandemia fue particularmente fuerte en el caso de Chile. De hecho, datos a nivel comparado demuestran que las tasas de mortalidad del país fueron bastante elevadas y aun cuando el sistema de salud no colapsó y sí logró disminuir casos al inicio, terminó sufriendo un largo estrés que afectó sobre todo a los sectores más pobres (Tariq et al. 2021). Sin ir más lejos, Bennett (2021) muestra como la llamada estrategia de "cuarentenas dinámicas" en que el gobierno cerraba algunas comunas mientras mantenía otras comunas colindantes abiertas, tuvo efectos negativos en los sectores de escasos recursos. La crisis llegó al punto en que muchos enfermos tuvieron que ser trasladados desde Santiago hacia otras regiones del país debido a la ausencia de camas de cuidado intensivo en la capital (La Tercera 2020).

No es casualidad entonces que el Ministro de Salud se convirtió en un personaje cuestionado por la población y es por ello que el Presidente no tuvo otra opción que reemplazarlo. El 13 de junio de 2020 asumió Enrique Paris, quien por mu-

En un trabajo publicado en abril de 2020 en el portal online Ciper Académico, los académicos Rafael González y Miguel Kiwi hicieron referencia a distintas recomendaciones de confinamiento provenientes desde la academia. Más detalles en https: / / www.ciperchile.cl/2020/04/16/covid-19-chile-no-esta-aplanando-lacurva-la-perdimos-de-vista / (Accedido el 28 de junio de 2021). 
chos años fue Presidente del Colegio Médico de Chile. A diferencia de Mañalich, Paris tenía el prestigio de ser una persona templada, considerado como un interlocutor válido tanto en la oposición como el gobierno. No era visto, en ese entonces, como un personaje político, sino que más bien como un experto que es capaz de buscar el bien común por sobre intereses partidarios. En efecto, Paris en más de una ocasión contradijo la opinión del Presidente Piñera y, a pesar de algunos conflictos, mantuvo, por gran parte de su gestión durante el 2020, una relación cordial con la Presidenta del Colegio Médico, Izkia Siches, quien usualmente ha sido crítica del actuar del gobierno frente a la pandemia y se ha transformado en un personaje político muy bien valorado (Castiglioni 2020b). Como se puede ver en el gráfico 1, el cambio ministerial fue muy bien evaluado por la ciudadanía: mientras que aproximadamente $70 \%$ de la población desaprobó la gestión de Jaime Mañalich durante el 2020, cerca de dos tercios de la población aprobó la labor de Enrique Paris a lo largo del resto del año.

Gráfico 1. Nivel (des)aprobación pública del Ministro de Salud de Chile durante el 2020 (en porcentaje)

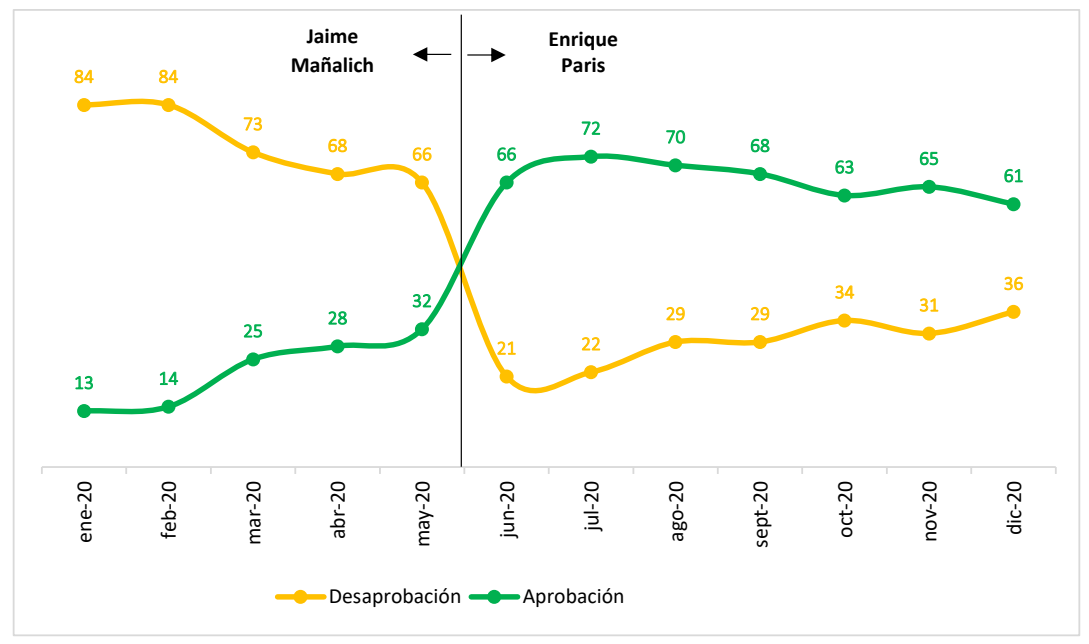

Fuente: CADEM. Elaboración propia.

Si bien es cierto que el cambio de Ministro de Salud dio paso a una gradual mejoría de la situación de la pandemia, Sebastián Piñera mantuvo durante todo el año muy elevados niveles de desaprobación ciudadana. De hecho, el presidente tuvo en promedio un nivel de desaprobación cercano al 70\% para todo el año y en ninguna medición logró un nivel de aprobación mayor al 30\% (ver gráfico 2). ¿A qué se deben estas elevadas cifras de reprobación hacia el presidente? A nuestro juicio, al menos tres factores nos ayudan a responder esta pregunta. En primer lugar, no hay que olvidar que a fines del 2019 el país experimentó un estallido social que fue pésimamente manejado por el mandatario y desde entonces su figura ha sido rechazada por amplios sectores de la ciudadanía, 
incluyendo una parte importante de quienes votaron por él en la elección presidencial del año 2017. En segundo lugar, el mal manejo de la pandemia tuvo, por cierto, un efecto negativo en la evaluación del presidente. En tercer y último lugar, hay otro factor explicativo que es sumamente importante: el impacto económico de la pandemia y la torpe respuesta del gobierno al respecto. A continuación, nos interesa detenernos en este tema en detalle, ya que es clave para comprender no solo la baja aprobación de Sebastián Piñera durante el 2020, sino que también las dificultades que ha experimentado para mantener unidos a los partidos políticos de su coalición de gobierno.

Gráfico 2. Nivel (des)aprobación presidencial en Chile durante el 2020 (en porcentaje)

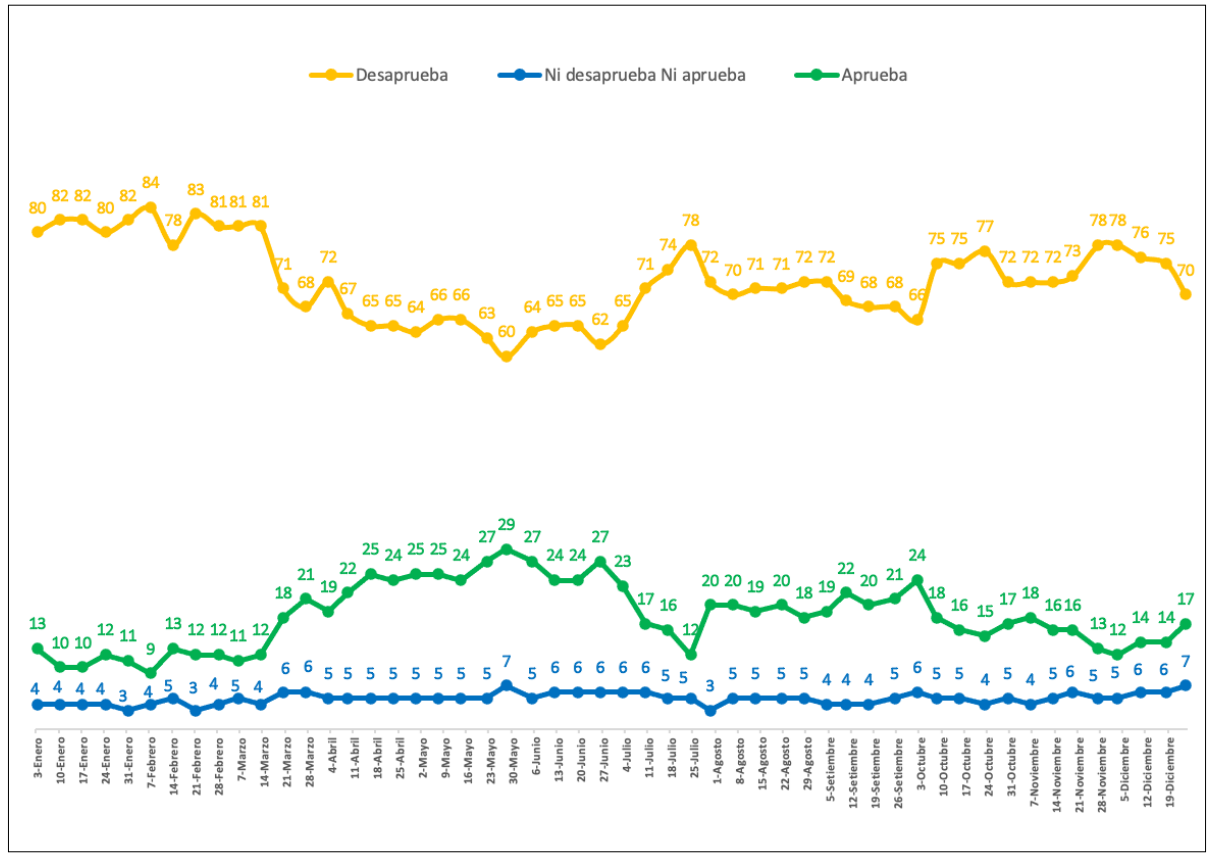

Fuente: CADEM. Elaboración propia.

La aparición del virus causante del COVID19 y las políticas de confinamiento trajeron consigo un fuerte impacto negativo sobre la economía a nivel mundial. Chile no fue la excepción a esta tendencia. Como se puede observar en la tabla 1, el segundo y el tercer trimestre del año fueron particularmente duros, tanto por la caída del PIB (-14.5 y -9.1, respectivamente) como por los niveles de desempleo (12.2 y 12.3, respectivamente). La dramática recesión económica y el aumento de desempleo generaron una serie de complicaciones para miles de personas a lo largo y ancho del país, de modo que el gobierno de Piñera se sentó a negociar con la oposición y logró sacar adelante un paquete de estímulo económico para hacer frente a las consecuencias sociales de la pandemia. Si 
bien es cierto que este acuerdo entre oposición y gobierno fue un logro importante de la administración de Piñera, este último adoptó una postura bastante cautelosa y gradual, lo cual es llamativo por la solidez macroeconómica del país en comparación a la gran mayoría de los países de la región latinoamericana (Blofield, Giambruno y Filgueira 2020). La ayuda económica solo adquirió mayor alcance y amplitud cuando la presión social y política fue aumentando, pero no evitó que se notase las limitaciones de los criterios tecnocráticos, especialmente en las medidas de focalización del apoyo social (Bitton 2020).

Tabla 1. Variación del PIB y de la tasa de desempleo en Chile para el 2020 (en porcentajes)

\begin{tabular}{lcc}
\hline & Variación Producto Interno Bruto (PIB) & Desempleo \\
\hline Enero-Marzo de 2020 & 0,3 & 8,2 \\
Abril-Junio de 2020 & $-14,5$ & 12,2 \\
Julio-Septiembre de 2020 & $-9,1$ & 12,3 \\
Octubre-Diciembre de 2020 & $-0,4$ & 10,3 \\
\hline
\end{tabular}

Fuente: INE y Banco Central. Elaboración propia.

Producto de una política económica conservadora y gradualista del Ejecutivo, el Poder Legislativo comenzó a adoptar cada vez un rol más protagónico, llevando a ciertos actores políticos y analistas a plantear el surgimiento de una suerte de "parlamentarización de facto" ${ }^{4}$. En efecto, dado que el gobierno es quien controla la iniciativa legal en materias de gasto público y sistema previsional, además de la ejecución del Presupuesto de la Nación, el Congreso discurrió un mecanismo inédito: para soslayar la restricción de aquellas leyes que pueden ser iniciadas por el Legislativo, congresistas presentaron una reforma constitucional para permitir que los ciudadanos puedan sacar una parte de sus fondos de pensiones para enfrentar la pandemia. Cabe destacar que durante la dictadura de Pinochet se estableció en el país un sistema de pensiones basado en la capitalización individual y no en la capitalización colectiva, es decir, cada individuo ahorra una parte de sus ingresos en cuentas personales que son gestionadas por las Administradoras de Fondos de Pensiones (AFP) y que según la ley entregan estos recursos a los individuos de vuelta solo al momento de jubilarse (Castiglioni 2001). Los parlamentarios de oposición levantaron la idea de que, ante la gravedad de la crisis económica y la débil respuesta por parte del Ejecutivo, resulta necesaria establecer una reforma constitucional para permitir que las AFP entreguen, de manera rápida y libre de impuestos, a cada persona que lo desee el 10\% de los fondos de pensiones acumulados.

El entonces presidente del Senado Jaime Quintana señaló en entrevista a La Tercera: “Si Piñera quiere seguir gobernando debe pasar a segunda línea y aceptar un parlamentarismo de facto" (Caro 2020). 
La propuesta de retiro anticipado del 10\% de los fondos de pensiones contó rápidamente con el apoyo mayoritario de la ciudadanía, lo cual se debe en parte a que existe una pésima evaluación ciudadana de las AFP en particular y del funcionamiento del sistema de pensiones en general. De hecho, las encuestas de fines del año 2019 realizadas por el Centro de Estudios Públicos (CEP) ${ }^{5}$ y del Centro de Cohesión y Conflicto Social (COES) ${ }^{6}$ revelan que más de la mitad de la ciudadanía opina que las pensiones es el problema al que el gobierno debería dedicar mayor esfuerzo. Pese a la fragmentación de las fuerzas de centroizquierda, prácticamente la totalidad de la oposición parlamentaria se mostró a favor de avanzar en esta reforma constitucional, la cual toca uno de los pilares del sistema económico instaurado por el régimen autoritario de Pinochet. Por su parte, el gobierno catalogó esta medida como irresponsable y partió del supuesto que tanto diputados como senadores de derecha se iban a oponer, de modo que resultaría imposible obtener un apoyo parlamentario de dos tercios para poder llevar adelante esta reforma constitucional.

No obstante, tal como indicamos al inicio de este artículo, la derecha se encuentra dividida internamente. En efecto, varias investigaciones (Alenda, Le Foulon y Súarez-Cao 2019; Alenda 2020; Alenda, Suárez-Cao y Le Foulon 2020) revelan que los militantes de los tres partidos de la coalición gobernante de derecha Evópoli, RN y UDI - tienen posturas divergentes frente al rol del estado en la economía y los temas morales, tratándose de divisiones que cruzan a cada uno de estos partidos. En otras palabras, es posible plantear que al interior de cada una de estas tres fuerzas políticas existen distintas facciones que tienen pareceres divergentes sobre diversas temáticas. A su vez, las disputas al interior de la derecha chilena se han visto exacerbadas producto de la irrupción de una nueva formación por fuera de la coalición gobernante: el partido Republicano liderado por José Antonio Kast ${ }^{7}$, el cual puede ser visto como un exponente criollo de la derecha populista radical (Luna y Rovira Kaltwasser 2021).

Las divergencias y tensiones al interior del bloque de derecha se tornaron particularmente visibles al momento de debatir el retiro anticipado de los fondos pensiones. Un número importante de parlamentarios de derecha comprendieron rápidamente que la presión ciudadana a favor del retiro del 10\% de los fondos previsionales era demasiado grande, sobre todo debido a la tardías y escasas ayudas económicas ofrecidas por el gobierno. Este último trató de mantener a su coalición unida mediante el ofrecimiento de ciertas mejorías en las medidas de apoyo económico. Sin embargo, la reacción del gobierno llegó muy tarde y no logró convencer a sus parlamentarios. Es así como a fines de julio

CEP 2019. Encuesta Nacional de Opinión Pública N 84. Disponible en: https://www.cepchile.cl/cep/encuestas-cep/encuestas-2009-2018/estudio-nacional-de-opinion-publica-n-84-diciembre-2019 [23 de marzo 2020].

6 Termómetro Social 2. 2019. Encuestas. Microdatos. Disponible en: https://www.microdatos.cl/termometro-social-2 [23 de marzo 2020].

Luego de la elección presidencial del año 2018, José Antonio Kast funda un movimiento político llamado "Acción Republicana" y posteriormente termina por fundar el año 2019 un partido político que se llama "Partido Republicano". Al día de hoy, ambas entidades tienen sus respectivas páginas web activas. 
una amplia mayoría del congreso aprobó la reforma constitucional que permite el retiro adelantado del 10\% de los fondos previsionales. Se trató de un verdadero terremoto para el gobierno y su coalición. Tan cierto es esto que Sebastián Piñera se vio obligado a realizar un cambio ministerial de proporciones, mediante el cual puso a reconocidas figuras de los distintos bandos de la derecha en ministerios claves: por un lado, el diputado Mario Desbordes (más cercano al sector dispuesto a realizar reformas estructurales) renunció al Congreso para asumir como Ministro de Defensa y, por otro lado, el senador Andrés Allamand (más cercano al sector que defiende el status quo) renunció al Congreso para asumir como Ministro de Relaciones Exteriores.

Para el gobierno resultaba primordial tratar de mantener unida a su coalición, sobre todo porque en octubre se realizaría el plebiscito constitucional que generaba una gran tensión al interior de los partidos de centroderecha. Tan cierto es esto, que en la práctica los tres partidos de la coalición dejaron a sus militantes en libertad de acción frente al tema, lo cual muestra la validez del argumento de las investigaciones de Alenda y colaboradoras respecto a la existencia de distintas sensibilidades que son transversales a Evópoli, RN y UDI (Alenda, Le Foulon y Súarez-Cao 2019; Alenda 2020; Alenda, Suárez-Cao y Le Foulon 2020). Por el contrario, el Partido Republicano y José Antonio Kast se mostraron como férreos opositores al cambio constitucional, reflejando así su intención de adoptar posturas claramente conservadoras. Tal como analizaremos en la siguiente sección en detalle, el resultado del referéndum tomó a todos por sorpresa y dejó una vez más en evidencia que el bando de derecha populista radical representa tan solo a una fracción muy reducida del electorado.

\section{EL PLEBISCITO CONSTITUCIONAL}

Quizás la consecuencia institucional más relevante del estallido social de fines del año 2019 fue el acuerdo de la clase política para fijar un itinerario de redacción de una nueva constitución. El primer paso consistió en la realización de un plebiscito, en donde la ciudadanía tuvo la posibilidad de tomar dos decisiones: por un lado, si estaba a favor o en contra de reformar la constitución de 1980 - aprobada durante la dictadura militar de Pinochet - y, por otro lado, si la constitución debiese ser reformada por una "convención mixta" (compuesta en un $50 \%$ por constituyentes elegidos directamente y en un $50 \%$ por miembros del actual congreso) o por "una convención constitucional" (asamblea conformada en su totalidad por constituyentes elegidos para este propósito). Aunque estaba inicialmente previsto para el 26 de abril de 2020, el plebiscito correspondiente fue postergado para el 25 de octubre del 2020 producto de la pandemia del COVID19.

A pesar de que para la fecha de la realización del plebiscito las cifras de contagio venían a la baja y muy pocas comunas del país se encontraban en cuarentena, existía mucha incertidumbre sobre el porcentaje de participación electoral. 
Chile es un país que desde la transición a la democracia ha venido mostrando crecientes niveles de abstencionismo electoral (PNUD 2020) y existe amplio consenso en el mundo académico que este es un gran problema del sistema político del país (Luna y Altman 2011; Castiglioni y Rovira Kaltwasser 2016; Morgan y Meléndez 2016). Sin duda que una baja participación electoral en el plebiscito abriría un debate respecto a la legitimidad del proceso, sobre todo debido a su relevancia para el devenir del país. Según los datos proporcionados por el Servicio Electoral (SERVEL), el número de votantes fue de 7.569.082, es decir un 50.9\% del padrón electoral, una cifra ligeramente mayor al porcentaje alcanzado en la segunda vuelta del 2017, en la que fue elegido Sebastián Piñera como presidente. Ahora bien, el perfil de quienes votaron para el plebiscito constitucional y la última elección presidencial no es idéntico, sobre todo porque aumentó la participación electoral en varias comunas de bajos ingresos. En otras palabras, es posible plantear que para el plebiscito constitucional se movilizaron votantes de bajos recursos que normalmente no participan en las elecciones (Vergara Perucich et al. 2020).

Todas las encuestas venían mostrando que las opciones "apruebo" y "convención constitucional" serian las ganadoras, pero había amplias dudas respecto a los porcentajes que obtendrían cada una de estas opciones. Los primeros cómputos reflejaron una realidad que se fue confirmando a lo largo que avanzaba el conteo de votos: un apoyo rotundo por modificar la constitución mediante una asamblea conformada en su totalidad por constituyentes elegidos para este propósito. En efecto, las cifras oficiales finales del SERVEL indican que un $78.28 \%$ del electorado votó por la opción "apruebo" y un 79\% votó por la opción "convención constitucional". A diferencia de lo sucedido en otros plebiscitos recientes como el del Brexit en el Reino Unido, en el caso de Chile la ciudadanía mayoritariamente tomó una clara decisión y esto ciertamente que ayudó a cementar la legitimidad del proceso. Sin embargo, los datos también reflejan lo que varios analistas consideran como la reaparición o más bien la demostración de la existencia de un voto de clase: en las tres comunas más pudientes de Santiago (Lo Barnechea, Las Condes y Vitacura) ganó la opción "rechazo", lo cual evidencia que gran parte (aunque no todos) los electores de mayores recursos se oponen a la reforma de la constitución (Vergara Perucich et al. 2020).

Más allá del debate sobre la composición socioeconómica de quienes votaron en el plebiscito, existen muy pocos análisis empíricos sobre este proceso eleccionario, en gran medida por la dificultad de llevar a cabo encuestas presenciales de representatividad nacional producto de la pandemia. Es por ello que en este artículo hacemos uso de una las pocas encuestas presenciales que se realizaron el país con posterioridad al plebiscito: un estudio de opinión pública representativo de la población urbana mayor de 18 años con un margen de error del $2.7 \%$ y que fue realizado por la Consultora Datavoz entre el 2 de noviembre del 2020 y el 7 de enero del 2021. Se trata de una encuesta, en cuyo trabajo de campo se entrevistó, cara a cara, a 1.500 personas distribuidas en 300 
Unidades de Muestreo Primarias (UMP). A pesar que el trabajo de campo se realizó en contextos de cuarentenas dinámicas, solo se reemplazaron $8 \mathrm{UMP}$. La tasa de respuesta fue del $70 \%$. El muestreo correspondiente es estratificado por macro-zonas con asignación de tamaños de muestra de manera proporcional para garantizar un número mínimo con el cual elaborar inferencias.

Como se puede observar en la tabla 2, los resultados de la encuesta de opinión empleada en el presente estudio, con respecto a las preferencias electorales, varían respecto a los resultados oficiales, aunque sin distorsionar sustantivamente el orden de preferencias. Quienes responden haber marcado la opción "apruebo" son 11 puntos porcentuales más (51.0\%) que el porcentaje correspondiente sobre el total de la población electoral (39.6\%). La opción "rechazo", por su parte, representa 4.5 puntos porcentuales menos $(6.5 \%)$ que el alcanzado en las ánforas (11.0\%). Respecto a la participación electoral en sí, un 34.2\% de encuestados respondió no haber ido a votar, es decir 14.9 puntos porcentuales menos de la cifra real. Finalmente, un $8.2 \%$ de encuestados se abstuvo de responder esta pregunta.

Tabla 2. Comparación de resultados oficiales del referéndum constitucional y los resultados de la encuesta de opinión (porcentaje)

\begin{tabular}{lrr}
\hline & Resultados oficiales sobre el total de la población electoral & Encuesta \\
\hline Apruebo & 39.6 & 51.0 \\
Rechazo & 11.0 & 6.5 \\
Nulo y blanco / (NS/NR) & 0.3 & 8.2 \\
No votó & 49.1 & 34.2 \\
Total & 100.0 & 100.0 \\
\hline
\end{tabular}

Fuente: SERVEL. Elaboración propia.

A continuación, revisamos y analizamos las estadísticas de la encuesta en cuestión para conocer los perfiles sociodemográficos, ideológicos y políticos de quienes apoyaron las dos opciones principales (y quienes no concurrieron a las urnas). Al hacer una radiografía sociodemográfica de los resultados (ver gráfico 3), identificamos antes que nada la importancia de la edad de los electores en la variación de los niveles de apoyo a la opción "apruebo", principalmente. Separados en cinco grupos etarios, los porcentajes de quienes respondieron haber votado a favor del cambio constitucional se reducen progresivamente del $55 \%$ en el intervalo más joven (18-29 años) al 44\% en el intervalo mayor, con un promedio del 52\% en los grupos intermedios (30-44 años, 45 a 54 años, 55 a 64 años). Es precisamente en el segmento más joven en el que la tasa de ausentismo es menor (37\%) en comparación con las cohortes mayores, especialmente del de 55-64 años (52\%) y de 65 años a más (51\%). En cambio, quienes marcaron la opción "rechazo", se mantienen entre el 6\% y 7\% en todos los grupos etarios. 
Este es un dato relevante porque revierte una tendencia que se observa en los procesos eleccionarios anteriores, a saber, que los jóvenes por lo general presentan menores niveles de participación que el resto de la población (Contreras y Navia 2013; Bargsted, Somma y Muñoz-Rojas 2019).

Gráfico 3. Distribución de preferencias "apruebo" vs. "rechazo" y ausentismo por grupo etario (porcentaje)



Otro tema que nos interesa abordar empíricamente es el debate respecto a la relevancia del voto de clase en el plebiscito constitucional (ver gráfico 4). En términos de niveles de ingreso, se cuenta con evidencia para sostener que efectivamente existió un voto de clase en la consulta ciudadana, lo cual se aprecia con mayor claridad en los segmentos más ricos (C1) y más pobres (E). En el primero, el voto por la opción "rechazo" alcanza un 29\%, el porcentaje más alto de respaldo a esta consigna si comparamos con los demás niveles de ingreso. En el segundo, el nivel de ausentismo llega al 53\%, porcentaje que es el mayor en comparación con los otros grupos. En general, a menor nivel de ingreso, mayor el porcentaje de encuestados que indicaron no haber votado. Finalmente, cabe agregar que el nivel de ingreso impacta levemente el voto por la opción "apruebo", el cual fluctúa entre el 61\% (C3) y 51\% (D), y solo cae al 40\% en el nivel de ingreso más bajo (E). En otras palabras, el argumento del voto de clase es válido, pero sobre todo cuando pensamos en los sectores muy ricos o muy pobres de la sociedad chilena: mientras los primeros tendieron a votar mayoritariamente y muchos de ellos por la opción "rechazo", los segundos en su mayoría no votaron y si lo hicieron se inclinaron más bien por la opción "apruebo". 
Gráfico 4. Distribución de preferencias "apruebo" vs "rechazo" y ausentismo por nivel de ingreso (porcentaje)

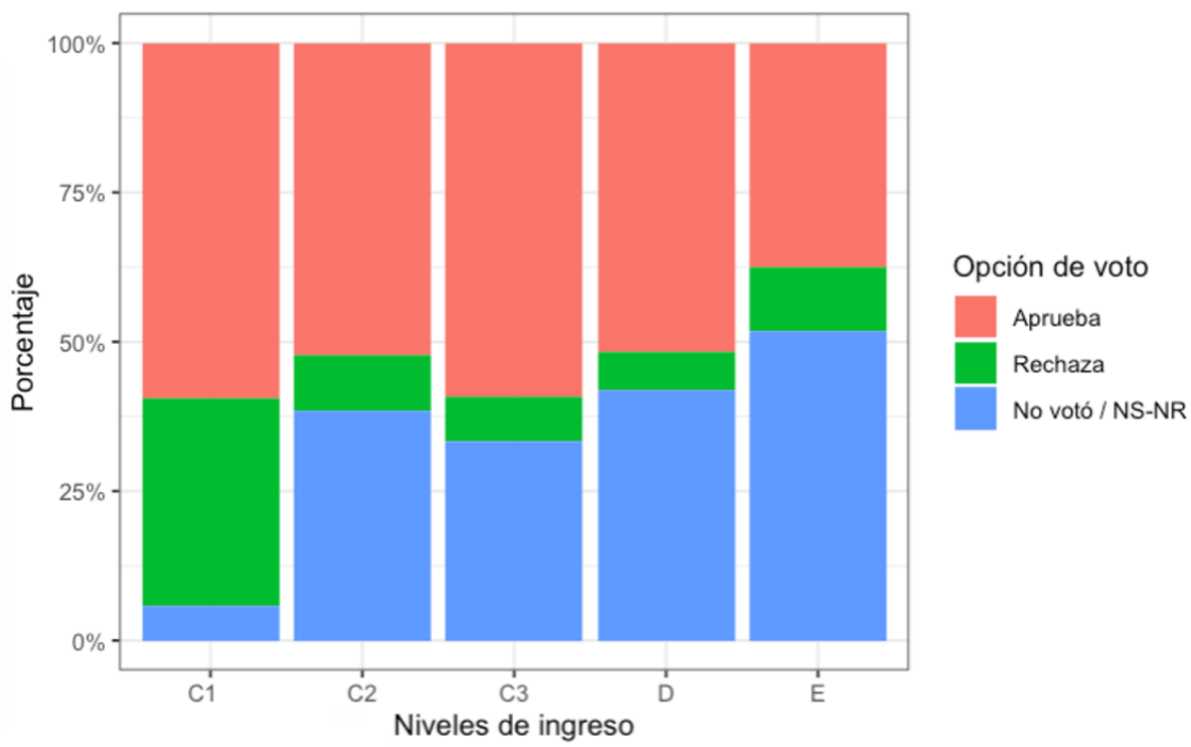

No pocos estudios empíricos indican que el nivel educativo es un variable clave para comprender procesos eleccionarios (Stubager 2010; Lancee y Sarrasin 2015; Surridge, 2016). ¿Hasta qué punto es esto cierto para el plebiscito constitucional en Chile? Como se puede observar en el gráfico 5, el nivel educativo del electorado explica la variación de votos a favor de la opción "apruebo". Agrupados los diferentes años de educación en tres grupos (educación básica y media incompleta, educación media completa, y educación superior completa o incompleta), se evidencia que a mayor nivel educativo aumentan los porcentajes de voto a favor de la opción "apruebo", pasando del 45\% al 49\% y al 58\%, respectivamente. Por su parte, el ausentismo disminuye conforme aumentan los años de educación, pasando del $51 \%$ al $43 \%$ y al 35\% en los grupos referidos. A su vez, es importante destacar que los porcentajes por la opción "rechazo" pasan del $4 \%$ en el grupo de nivel más bajo, al $8 \%$ en el nivel intermedio y al $7 \%$ en el superior. 
Gráfico 5. Distribución de preferencias "apruebo" vs "rechazo" y ausentismo por nivel educativo (porcentaje)

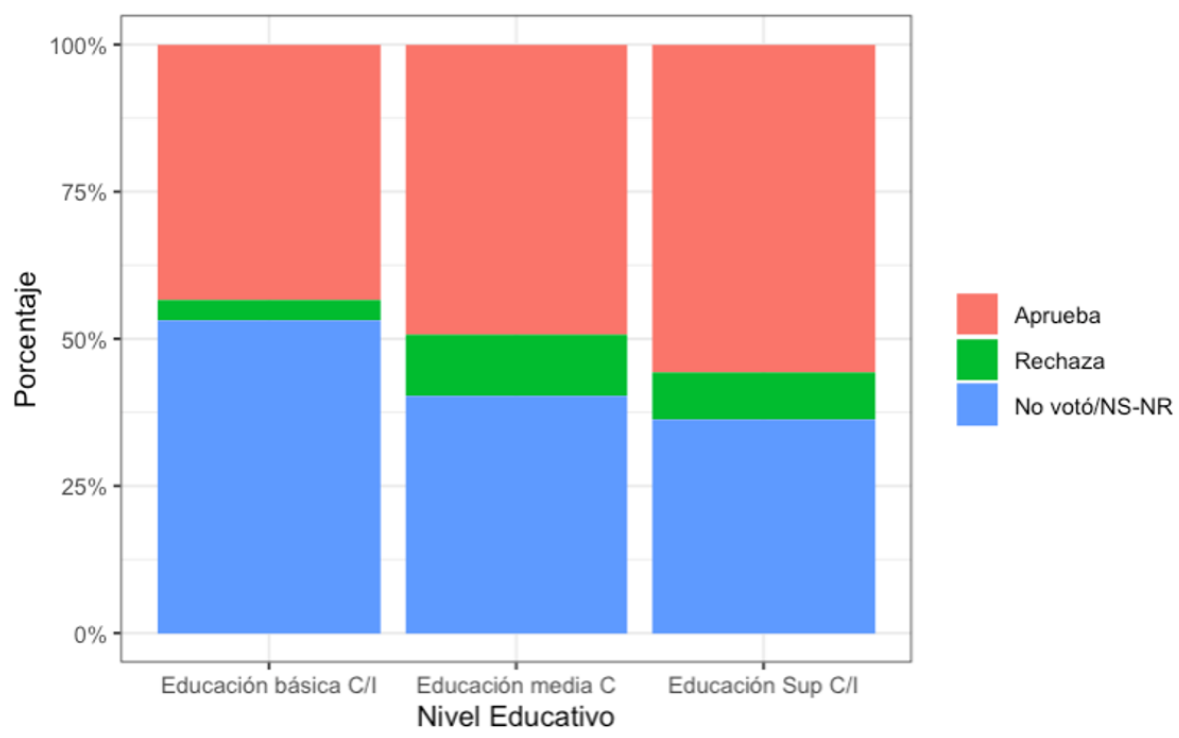

Dado que el resultado del plebiscito fue contundente, es posible plantear que las preferencias ideológicas de quienes votaron por la opción "apruebo" y "rechazo" deberían ser bastante diferentes. Mientras que el voto "rechazo" debería aglutinar a aquellas personas que profesan ideas de derecha más radical, el voto "apruebo" debería ser mucho más heterogéneo ideológicamente, abarcando personas desde la derecha moderada hasta quienes se posicionan más a la izquierda. Esa fue la evidencia disponible en encuestas previas a la realización del plebiscito (Sajuria 2020). En efecto, el análisis empírico de la encuesta realizada para este estudio demuestra que la magnitud del voto a favor del "apruebo" implicó que personas con diferentes matrices ideológicas y políticas terminaron inclinándose por esta opción. Para categorizar el signo ideológico de los encuestados, tomamos como base sus respectivos autoposicionamientos en una escala del 0 al 10, donde 0 representa la extrema izquierda y 10 la extrema derecha (ver gráfico 6). Etiquetamos como de "izquierda", a quienes se ubicaron entre 0 y 3; de "centro", a quienes respondieron entre 4 y 6; y de "derecha", a quienes se posicionaron entre el 7 y el 10. Entre quienes respondieron haber apoyado el inicio de un proceso constitucional $(53.1 \%$ del conjunto de la población excluyendo quienes no respondieron la pregunta de posicionamiento ideológico), encontramos a quienes catalogan como centro (28.1\%), de izquierda (20.2\%) e incluso de derecha (4.5\%). En cambio, entre quienes estuvieron en contra de propiciar un cambio constitucional $(7.2 \%)$, la izquierda está apenas representada $(0.5 \%)$, predominando a quienes ocuparon lugares de derecha $(3.7 \%)$ y de centro (3.1\%). Quienes respondieron no haber votado (o sencillamente no respondieron esta pregunta), predominan electores ubicados a sí mismos en el centro del espectro ideológico. 
Gráfico 6. Distribución de preferencias "apruebo" vs "rechazo" y ausentismo por auto-posicionamiento en el eje izquierda/derecha (porcentaje)

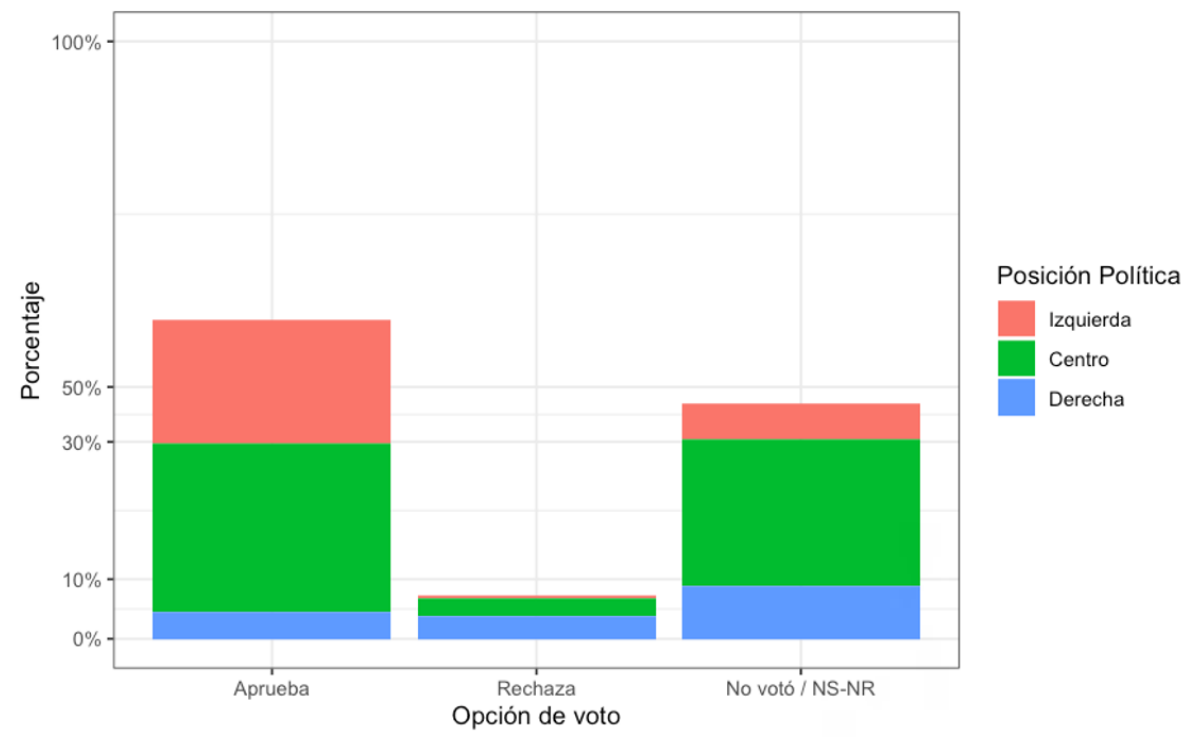

Una forma alternativa de responder la pregunta sobre la homogeneidad/heterogeneidad de quienes votaron por la opción "apruebo" o "rechazo", consiste en analizar las preferencias según el auto-posicionamiento de los encuestados en el eje conservador/liberal. Como se puede observar en el gráfico 7 , el auto-posicionamiento en términos de valores morales efectivamente explica las preferencias por endosar distintas opciones en el plebiscito. En un continuo del 0 al 10, donde 0 es conservador y 10 es liberal, etiquetamos como "conservadores" a quienes se ubicaban entre 0 y 3 , como "moderados" entre quienes ocupaban los lugares del 4 al 6 y como "liberales" a quienes se percibían entre los puntos 7 al 10. Del total de encuestados que votaron por el "apruebo" (y se posicionaron valóricamente en el continuo de conservador/liberal), califican una variedad de "liberales" (sumaron el $23.4 \%$ del total de quienes respondieron la respectiva pregunta de autoposicionamiento), "moderados" (18.5\%) e incluso "conservadores" (6.5\%), lo cual refleja un equilibrio valórico entre quienes optaron por esta opción. En cambio, entre quienes votaron por el "rechazo" ( $8.4 \%$ del total de quienes respondieron la respectiva pregunta de autoposicionamiento), la opción moderada fue mayor $(3.9 \%)$ a la conservadora $(2.7 \%)$ y a la liberal (1.8). Entre quienes respondieron no haber votado (o no haber respondido la pregunta electoral correspondiente), la diversidad ideológica se repite como entre los que "aprobaron", aunque con predominio de los catalogados como "moderados". 
Gráfico 7. Distribución de preferencias "apruebo" vs "rechazo" y ausentismo por auto-posicionamiento en el eje conservador/liberal (porcentaje)

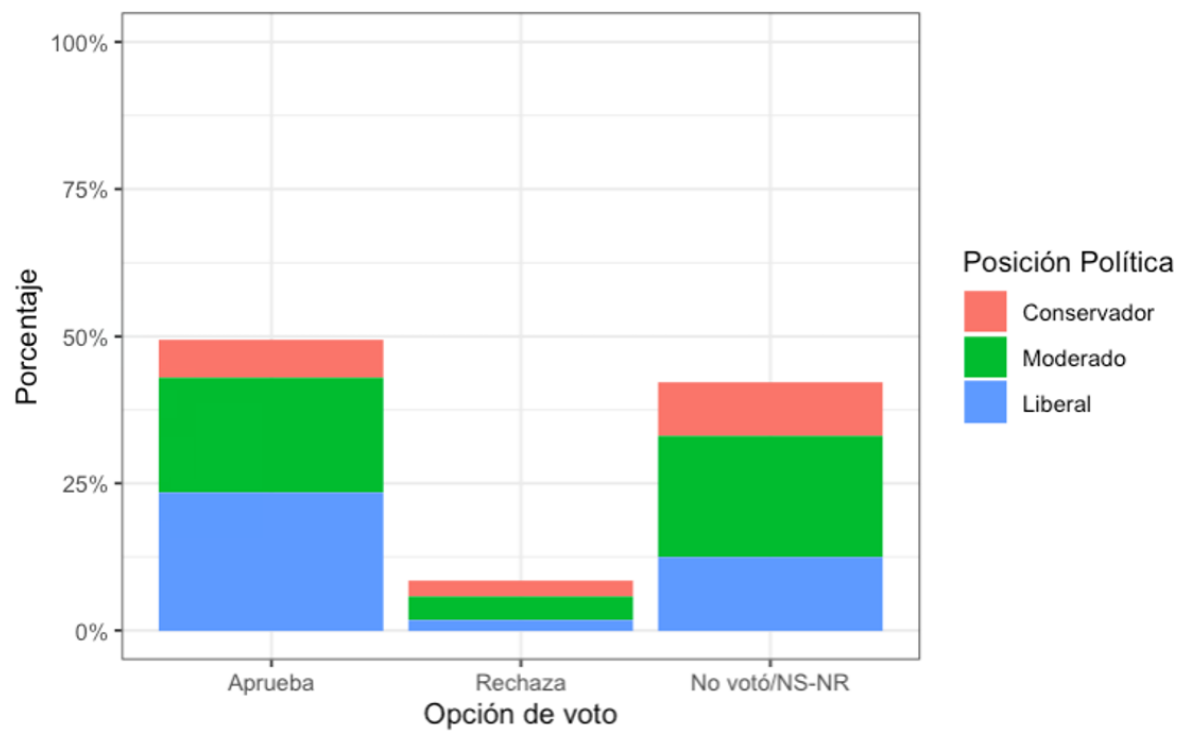

Finalmente, otro dato de la encuesta que ayuda a testear el argumento de que el voto "apruebo" es ideológicamente heterogéneo y el voto "rechazo" es ideológicamente homogéneo consiste en analizar qué opción tomaron los votantes en la elección presidencial del año 2017. En efecto, la diversidad política del endoso a la opción "apruebo" se vio reflejado en el porcentaje de electores de Piñera que terminaron marcando esta opción. Si bien la mayoría de quienes apostaron por modificar la constitución indicó haber votado por Guiller en la segunda vuelta de las elecciones del 2017 (40.7\%), la proporción de quienes respondieron haber votado por Sebastián Piñera (19.8\%) es relevante (ver gráfico 8). En cambio, entre quienes votaron por la opción del "rechazo", son principalmente electores de quien fuera el candidato presidencial de la coalición de centroderecha "Chile Vamos" en el 2017. Quienes hace cuatro años dieron su voto a Sebastián Piñera, terminaron dispersándose entre las opciones del "apruebo" y del "rechazo", e incluso de sencillamente no participar en el proceso electoral. Este dato refuerza el argumento de que la derecha en Chile está dividida internamente (Alenda, Le Foulon y Súarez-Cao 2019; Alenda 2020; Alenda, SuárezCao y Le Foulon 2020), lo cual se ha potenciado aún más después del estallido social y sobre todo a raíz de la aparición del Partido Republicano liderado por José Antonio Kast (Rovira Kaltwasser 2019, 2020). 
Gráfico 8. Distribución de preferencias "apruebo" vs "rechazo" y ausentismo por votación en la segunda vuelta electoral del año 2017 (porcentaje)

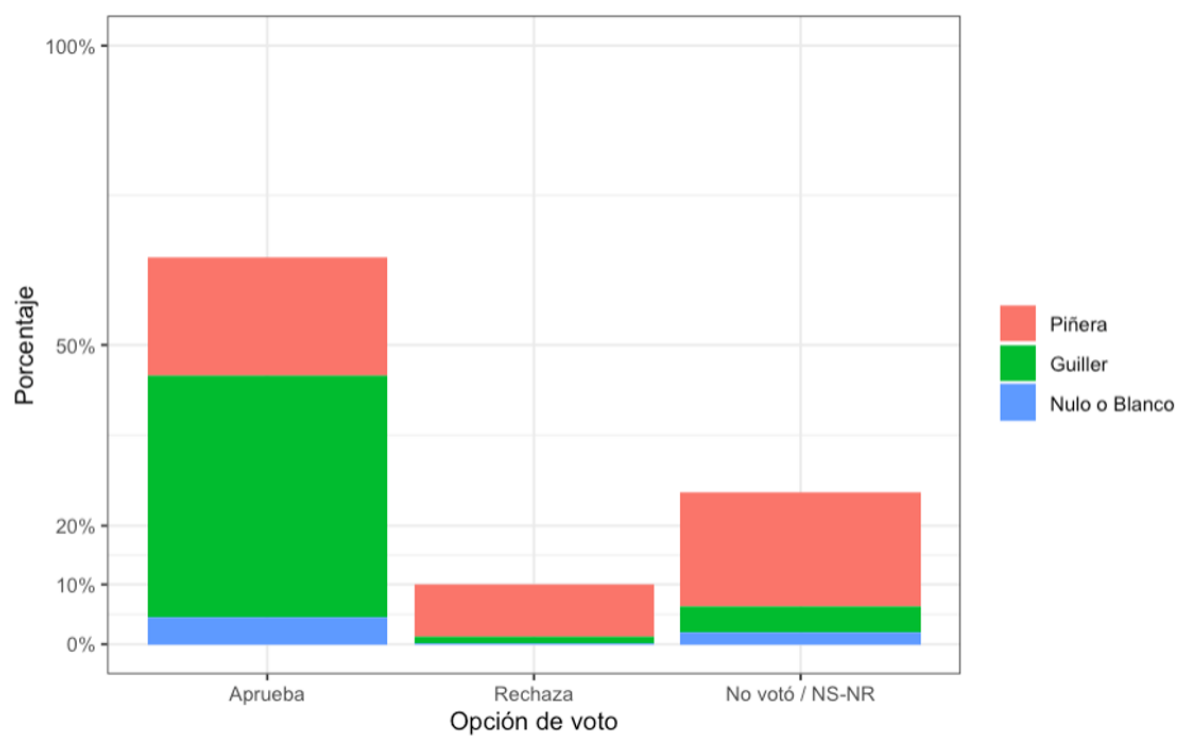

En resumen, los datos descriptivos analizados hasta ahora demuestran que la distribución de votantes en ambas opciones es diametralmente distinta, pero no en términos de un solo eje ideológico o socioeconómico. Así, como hemos expresado en los párrafos anteriores, el "rechazo" acumula a un grupo distintivo de la población, principalmente de derecha, conservador y con predominancia de personas de altos ingresos. Al contrario, el "apruebo" es una muestra mucho más representativa de la población, agrupando a personas de todos los sectores económicos, sociales y políticos. El plebiscito, al contrario de experiencias como los referéndums de Brexit o del proceso de paz colombiano, no generó dos polos antagónicos alrededor de sus opciones. Lo que sí logro fue encapsular a un segmento particular de la derecha chilena detrás de la opción de mantener el texto constitucional de 1980.

El siguiente paso en nuestro análisis consiste en hacer una revisión más exhaustiva detrás de las motivaciones de voto en el plebiscito. Como ya hemos observado, la composición del voto por la opción "apruebo" es profundamente heterogénea, con una diversidad poco observada con anterioridad en el electorado chileno. Sin embargo, la situación opuesta ocurre en el caso del voto por la opción "rechazo", donde el porcentaje de gente que prefirió esa alternativa parece ser muy bajo y, además, homogéneo. En consecuencia, nuestro análisis continúa con la estimación de un modelo de regresión logística en la que buscamos examinar los potenciales predictores del voto por la opción "rechazo". Con ello, trataremos de buscar qué es lo que hace particularmente distinto a este segmento. Ya que nuestra intención es comparar el voto "rechazo" versus 
"apruebo", decidimos dejar fuera de nuestro modelo de regresión a quienes dijeron que no habían votado en el plebiscito y a quienes no respondieron la pregunta. Nuestra variable dependiente es dicotómica, donde 0 significa que la persona declara haber votado por la opción "apruebo", y 1 si es que la persona dice haber votado por la opción "rechazo". No obstante lo anterior, como una forma de analizar la robustez de nuestros resultados, hemos estimado modelos multinomiales en los que ocupamos a los votantes del "apruebo" (el grupo más grande) como la base de comparación. Dichos modelos son presentados en el apéndice, pero hemos preferido enfocarnos en la interpretación del modelo de regresión logística por proveernos de mayor claridad a la hora de discutir los resultados.

Como valores predictores, partimos incluyendo las variables que miden el auto-posicionamiento de los encuestados en dos escalas que van de 0 a 10. La primera representa el eje izquierda (0) versus derecha (10), mientras el segundo mide el eje conservador (0) versus liberal (10). Además, en línea con investigaciones académicas sobre la derecha populista radical, incorporamos una variable midiendo el acuerdo con la idea que la inmigración afecta negativamente el empleo de la población local. De hecho, existe acuerdo en la literatura comparada sobre fuerzas de derecha populista radical que su apoyo electoral descansa por sobre todo en preferencias "nativistas", es decir, la idea de que la nación debe ser habitada solo por miembros de la población nativa y que tanto ideas como personas foráneas ponen en riesgo la supuesta homogeneidad del estado-nación (Mudde 2007; Mudde y Rovira Kaltwasser 2018).

El resto de las variables que incluimos en el modelo de regresión logística corresponde a elementos sociodemográficos. Además de los controles tradicionales por sexo, edad, nivel educacional y nivel socioeconómico, agregamos una medición sobre la identificación religiosa (católica, evangélica, y otros, incluyendo no creyentes y agnósticos) y la auto-identificación racial (como blanco, en contraste a otras categorías como pueblos originarios, mestizos y negros, entre otros). Al igual como con el tema de la inmigración, estas últimas dos variables también están relacionadas con la literatura sobre el surgimiento de la derecha extrema, tanto en Europa como en otras regiones del mundo. En efecto, investigaciones sobre la irrupción de la derecha populista radical en países como Brasil (Bolsonaro) y Estados Unidos (Trump) demuestran que el apoyo a estas fuerzas electorales se explica en gran parte por grupos evangélicos y la cuestión racial (e.g. Whitehead et.al. 2018; Amaral 2020).

Los hallazgos del modelo de regresión logística se presentan en el grafico 9, el cual muestra los resultados expresados en probabilidades predichas para cada variable. Con ello, la forma de interpretación consiste en observar si esas probabilidades son significativamente distintas - en términos estadísticos - de una probabilidad de 0.5 , en la que cada resultado tiene la misma probabilidad. Es decir, un resultado donde la probabilidad predicha es superior a 0.5, implica que la relación es positiva entre esa variable y la probabilidad de voto por el rechazo; lo opuesto ocurre si es que el valor es inferior a 0.5. Para estimar 
la significancia estadística de las probabilidades predichas, ocupamos un mecanismo de simulaciones pseudo-bayesianas con el fin de generar una distribución posterior. La estimación reportada corresponde a la mediana de dicha estimación, mientras que el intervalo corresponde a las observaciones entre el $2.5 \%$ inferior y el $97.5 \%$ superior de la distribución. Con ello, inferimos que los intervalos que contienen el valor de probabilidad de 0.5 no son estadísticamente significativos.

Gráfico 9. Prediciendo el voto por el "rechazo"

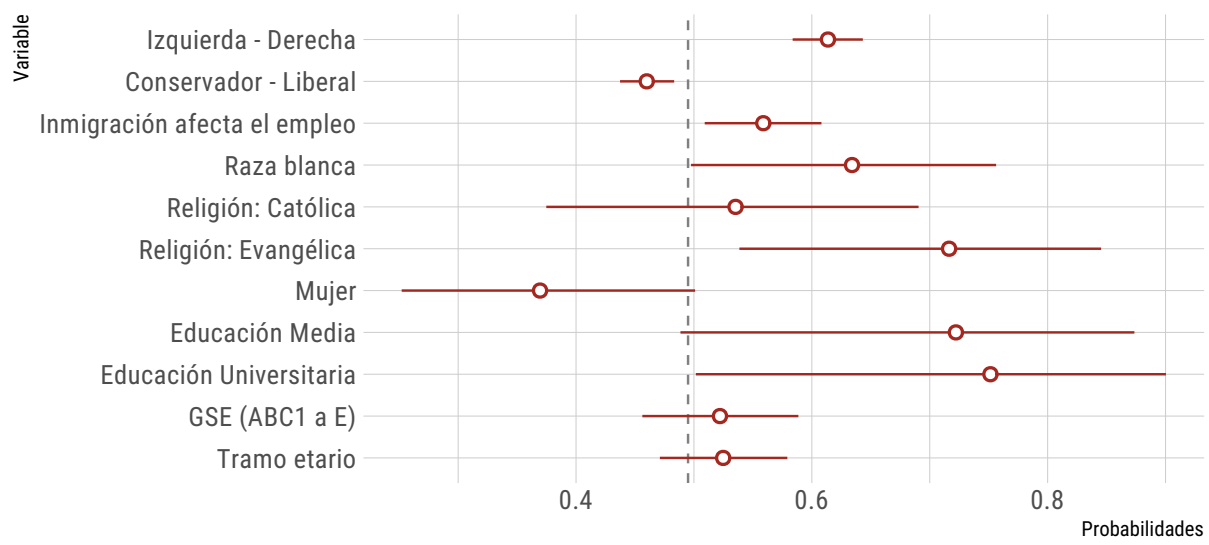

Partiendo por las variables ideológicas, observamos que, en promedio, los votantes de la opción "rechazo" se ubican más a la derecha que el resto de la población. Asimismo, se auto-identifican más como conservadores que liberales. Esto es consistente con los datos descriptivos arriba presentados y, además, con el argumento de que la opción "rechazo" fue una opción principalmente defendida por dirigentes de la derecha que presiona por mayor radicalización antes que moderación programática.

Es importante considerar con este resultado, y con todas las interpretaciones del modelo, que esto no es lo mismo que decir que todos los que son de derecha y conservadores votaron por la opción "rechazo". Como se puede observar en nuestros resultados descriptivos de más arriba, esto no es correcto, ya que cerca de la mitad de quienes se declaran de derecha (y un porcentaje aún mayor de quienes dicen haber votado por Sebastián Piñera) dicen haber votado por la opción "apruebo". Lo que nuestros resultados muestran es que, entre quienes votaron "rechazo", la mayoría se ubica más a la derecha que quienes votaron "apruebo".

La otra variable más actitudinal, relacionada con preferencias ideológicas, consiste en el acuerdo con la idea que la inmigración afecta el empleo. Como vemos en el gráfico 9, esta idea está más presente entre quienes dicen haber votado por 
la opción "rechazo" que por quienes dicen haber votado por la opción "apruebo". Esto es un indicio de un incipiente nativismo en parte importante de los votantes por la opción "rechazo", con lo cual muestran una semejanza importante con los votantes que otras partes del mundo apoyan a fuerzas populistas de derecha radical. De hecho, como ya adelantamos más arriba, la combinación entre auto-posicionamiento ideológico a la derecha, preferencias nativistas, la vinculación religiosa con visiones evangélicas y las ideas de supremacía blanca están en la base de la construcción de la derecha populista radical. Por ello, incorporamos una variable de identificación racial en la encuesta, la que según se puede ver en los resultados, tiene una relación significativa con el voto por la opción "rechazo". Es decir, entre quienes votaron "rechazo", es más común que se identifiquen como blancos que como otras razas. En términos religiosos, también observamos una diferencia significativa entre quienes son evangélicos. En promedio, ser evangélico aumenta la probabilidad predicha de votar por la opción "rechazo" en una alta proporción (sobre 20 puntos porcentuales). Con ello, los datos demuestran una combinación entre derecha, nativismo, religiosidad evangélica e identificación racial.

En otros aspectos demográficos, observamos que el voto por la opción "recha$\mathrm{zo}^{\prime \prime}$ es predominantemente masculino (aunque no es estadísticamente significativo), y con un porcentaje más alto de personas con educación universitaria. Quizás algo interesante es comparar los resultados de grupos socioeconómicos en relación con la noción tradicional de que el voto por la opción "rechazo" es predominantemente de altos ingresos. Como discutimos más arriba, la concentración espacial del voto "rechazo" en las comunas más pudientes de la ciudad de Santiago han generado esta narrativa. Sin embargo, nuestros datos contrastan con ese relato al mostrar que no hay una relación significativa entre el grupo socioeconómico y el voto "rechazo". Una hipótesis para explicar esta diferencia tiene que ver con el nivel de análisis. Los análisis agregados - como los que se realizan a nivel comunal - tienen grandes riesgos de falacias ecológicas, sobre todo cuando se analizan decisiones individuales como la opción de voto. Nuestro análisis, dado su nivel individual, debiese tener un mayor nivel de validez, lo que implica que el voto "rechazo" no es predominantemente más rico, sino que la combinación especial de variables individuales en algunos sectores del país generan esa percepción.

Es importante mencionar que estos resultados son confirmados, en gran medida, al analizarlos en el modelo multinomial incluido en el apéndice (tablas A1 y A2). Solo uno de nuestros resultados no se mantiene: desaparece la relación significativa entre la identificación con la raza blanca y el voto por el "rechazo". Por lo mismo, creemos que hay que ser cautelosos con la interpretación de esa relación en particular y, por lo tanto, creemos que es necesario llevar a cabo más investigaciones que incluyan la variable de identificación racial para saber el rol que puede jugar en el potencial surgimiento y consolidación de un electorado de derecha populista radical. No obstante, el resto de los resultados ya comentados se mantienen en los modelos de regresiones multinomiales, lo que 
nos da confianza sobre su robustez y por ello nos parece plausible plantear que la opción "rechazo" logró movilizar a un tipo de votante que en otras latitudes apoya a fuerzas populistas de derecha radical.

\section{CONCLUSIONES}

Durante el año 2020 el gobierno de Piñera no fue capaz de conducir las distintas visiones que existen al interior de los tres partidos de su gobierno. La aparición de una fuerza de derecha populista radical (Partido Republicano liderado por José Antonio Kast) ha dificultado aún más la capacidad de generar consensos al interior de la derecha. Tanto el debate respecto al retiro anticipado de los fondos provisionales como respecto al cambio constitucional revelan que la derecha de hoy en día está marcada por dinámicas centrifugas que difícilmente desaparecerán en el futuro cercano. El análisis sobre los principales hechos políticos del 2020 nos conducen a corroborar que la derecha chilena no debe ser pensada como un grupo homogéneo, sino como un sector político donde coexisten distintas tradiciones políticas y sensibilidades ideológicas (Alenda, Le Foulon y Súarez-Cao 2019; Alenda 2020; Alenda, Suárez-Cao y Le Foulon 2020). En este artículo hemos tratado de mostrar que esta diversidad se ha vuelto un problema producto del estallido social de fines del 2019 y la pregunta respecto a cómo manejar la pandemia del COVID-19.

Por un lado, es posible observar un sector de derecha más moderado, capaz de comprender las causas del ciclo de movilizaciones sociales y la necesidad de una nueva constitución con un rol más protagónico del Estado. De hecho, el control parcial del sistema de salud por parte del Estado ha demostrado que moverse hacia políticas sociales de corte más universalista no es una quimera. A su vez, un número importante de diputados y senadores de derecha aprobaron el retiro anticipado de las cuentas individuales de las AFP, lo cual pone en evidencia que hay un segmento de la derecha que está dispuesto a tranzar algunos de los pilares del modelo económico implantando durante la dictadura de Pinochet.

Por otro lado, existe un grupo de la derecha que es más ortodoxo y que, durante el 2020, encontró en la consigna del "rechazo" una suerte de escudo protector de sus creencias y preferencias ideológicas. En este artículo hemos mostrado evidencia empírica sobre este grupo de votantes, quienes son muy homogéneos en términos sociopolíticos y esto los diferencia notoriamente de quienes votaron a favor de la opción "apruebo". En efecto, el análisis estadístico que presentamos en el presente artículo permite reconocer en los votantes de la opción "rechazo" características propias de la derecha populista radical en otras partes del mundo. Se trata de un grupo conservador, de derecha, que manifiesta un incipiente nativismo, afines a visiones evangélicas y supremacistas raciales, y no necesariamente de mayores ingresos como se había especulado en base a datos electorales agregados geográficamente. Si bien es cierto que 
estudios previos habían detectado una demanda por atractivos populistas en el país (Meléndez y Rovira Kaltwasser 2019), estaríamos ante la constitución de un sector minoritario pero influyente, un elitismo supresor de demandas ciudadanas (Rhodes-Prurdy y Rosenblatt 2021) con un carácter propio de las derechas extremas más perjudiciales para el sistema democrático.

La literatura en política comparada revela que el surgimiento de una derecha populista radical implica un desafío mayúsculo, en tanto promueve ideas y prácticas iliberales que erosionan los cimientos de la democracia (Mudde 2007; Mudde y Rovira Kaltwasser 2018). Evidencia de otras latitudes muestra que la postura de la derecha convencional es clave, ya que es muy diferente si ella está dispuesta a unir fuerzas y adoptar posturas extremas (como en el caso del Partido Republicado en los Estados Unidos) o más bien si se distancia de la derecha populista radical y mantiene posturas más bien moderadas (como en el caso del Partido Demócrata Cristiano en Alemania) (Bale y Rovira Kaltwasser 2021). En consecuencia, es muy importante que futuros estudios para el caso de Chile pongan especial atención en cómo interactúa la derecha populista radical con la derecha convencional. El hecho de que ambas hayan armado una lista electoral conjunta para la elección de la convención constitucional es una señal de alerta, en tanto pone de manifiesto que ambas derechas parecieran estar dispuestas a colaborar con el fin de obtener un mayor caudal de votos.

Por su parte, en el campo político opuesto existe una alta diversidad de preferencias programáticas y fragmentación política, lo cual pone obstáculos para resolver problemas de acción colectiva que supongan que el proceso constitucional sea aprovechado constructivamente para la comulgación de una agenda más progresista como base para un programa de gobierno de centroizquierda. El débil enraizamiento de los partidos políticos en la sociedad civil, su difícil relación con los movimientos sociales y su lenta renovación dirigencial, abonan como dificultades para representar las altas y diversas expectativas levantadas en los últimos años. Además, la ausencia de polarización como producto de los resultados del plebiscito (en comparación con los casos del Brexit británico y proceso de paz colombiano), ha llevado a las élites de este sector a bajar la guardia y soslayar la amenaza al sistema democrático que representa una derecha populista radical que por ahora pareciera ser capaz de establecer alianzas con la derecha convencional.

El fraccionamiento de la izquierda y su incapacidad para generar una mejor vinculación tanto entre sí como con la sociedad civil permite pensar que existen posibilidades de que la derecha pueda seguir controlando el poder ejecutivo, sin que necesariamente tenga una mayoría en el congreso. Un escenario de este tipo no es auspicioso para el país, sobre todo si la derecha convencional y la derecha populista radical se mantienen unidas, ya que esto sin duda alguna que generará mayores niveles de polarización y pondrá a prueba la resiliencia del sistema democrático del país. A su vez, el proceso constitucional que se inició a fines del 2020 trae consigo una serie de oportunidades y riesgos. Todo indica entonces que los próximos años seguirán estando marcados por la incertidum- 
bre política. En gran medida, el futuro del país depende de la capacidad o no que tendrán las élites tanto de sintonizar como de encausar adecuadamente las demandas de una ciudadanía que se ha vuelto cada vez más exigente.

\section{REFERENCIAS}

Alenda, Stephanie, ed. 2020. Anatomía de la derecha chilena: Estado, mercado y valores en tiempos de cambio. Santiago: Fondo de Cultura Económica.

Alenda, Stephanie, Carmen Le Foulon y Julieta Suárez-Cao. 2019. “La batalla por las ideas en tiempos posideológicos: Adaptaciones y permanencias ideológicas en la nueva centro-derecha chilena". Revista de Sociologia e Política, 27(70): 1-18.

Alenda, Stephanie, Julieta Súarez-Cao y Carmen Le Foulon. 2020. “La derecha chilena en la encrucijada: la contrahegemonía de los liderazgos subnacionales y solidarios". Revista CIDOB d'Afers Internacionals 126: 65-87.

Amaral, Oswaldo. 2020. "The victory of Jair Bolsonaro According to the Brazilian Electoral Study of 2018". Brazilian Political Science Review 14(1): 1-13.

Bale, Tim y Cristóbal Rovira Kaltwasser (eds.). 2021. Riding the Populist Wave: Europe's Mainstream Right in Crisis. Cambridge: Cambridge University Press.

Bargsted, Matias, Nicolás Somma y Benjamín Muñoz-Rojas. 2019. "Participación electoral en Chile. Una aproximación de edad, período y cohorte". Revista de Ciencia Política 39(1): 75-98.

Bennett, Magdalena. 2021. "All things equal? Heterogeneity in policy effectiveness against COVID-19 spread in Chile". World Development 137: 105-208.

Bitton, Mathis. 2020. 8 de julio. "Chile and the Perils of Technocracy". National Review. Recuperado el 13 de julio de 2020 de https://www.nationalreview.com/2020/07/chile-and-the-perils-of-technocracy/

Blofield, Merike, Cecilia Giambruno y Fernando Filgueira. 2020. “Policy expansion in compressed time: Assessing the speed, breadth and sufficiency of post-COVID-19 social protection measures in 10 Latin American countries". ECLAC Social Policy Series 235.

Caro, Isabel. 2020, 13 de marzo. "Jaime Quintana: "Si Piñera quiere seguir gobernando debe pasar a segunda línea y aceptar un parlamentarismo de facto""'. La Tercera. Recuperado el 13 de julio de 2021 de https:/ / www.latercera.com/politica/noticia/jaime-quintana-si-pinera-quiere-seguir-gobernando-debe-pasar-a-segunda-linea-y-aceptar-un-parlamentarismo-de-facto/K23A5LL63FHX3IPKEHZFTNREK4/

Castiglioni, Rossana. 2001. "The Politics of Retrenchment: The Quandaries of Social Protection Under Military Rule in Chile, 1973-1990". Latin American Politics \& Society 43(4): 37-66.

Castiglioni, Rossana. 2020a, 8 de abril. "Chile's New (Fragile) Social Truce". Americas Quarterly. Recuperado el 13 de julio de 2021 de https://americasquarterly.org/article/ chiles-new-fragile-social-truce/

Castiglioni, Rossana. 2020b. "La política chilena en tiempos de pandemia. Entre la desmovilización y la crisis sanitaria". Revista Nueva Sociedad 287: 68-79.

Castiglioni Rossana y Cristóbal Rovira Kaltwasser. 2016. "Introduction. Challenges to Political Representation in Contemporary Chile". Journal of Politics in Latin America 8(3): 3-24.

Contreras, Gonzalo y Patricio Navia. 2013. “Diferencias generacionales en la participación electoral en Chile, 1988-2010". Revista de Ciencia Política 33(2): 419-441.

Donoso, Sofia y Marisa von Bülow (eds). 2017. Social Movements in Chile: Organization, Trajectories and Political Consequences. New York: Palgrave Macmillan.

El Mercurio. 2020, 21 de marzo. "Mañalich y comparaciones con tragedias de España e Italia: "Se puede decir con entera autoridad... eso no pasará acá"". Emol.com. 
Recuperado el 22 de julio de 2021 de https://www.emol.com/noticias/Nacional/2020/03/21/980569/Manalich-ministro-Italia-Espana.html

Fontaine, Arturo. 2021. La pregunta por el régimen politico. Conversaciones chilenas. Santiago: Fondo de Cultura Económica.

Freidenberg, Flavia y Julieta Suárez-Cao. 2021. “Creando redes de mujeres en una disciplina masculinizada: el caso de la Red de Politólogas". Polis. Revista Latinoamericana (59) http://dx.doi.org/10.32735/S0718-6568/2021-N59-1592.

Heiss, Claudia. 2020. "Entre el Estallido Social y la Pandemia". Análisis Carolina. 18/2020.

La Tercera. 2020, 29 de enero. "Dougnac indica que a la fecha se han realizado 715 traslados aeromédicos de pacientes Covid en el país y ahora "es momento que Santiago brinde apoyo" a las regiones". Recuperado el 22 de julio de 2021 de https:/ / www.latercera. $\mathrm{com} /$ nacional/noticia/mas-de-715-pacientes-covid-han-sido-trasladados-por-viaaerea-en-lo-que-va-de-la-pandemia-en-el-pais/GB6IAK2ODFCONFJG4J66HXZQLI/

Lancee, Bram y Oriane Sarrasin. 2015. “Educated Preferences or Selection Effects? A Longitudinal Analysis of the Impact of Educational Attainment on Attitudes Towards Immigrants". European Sociological Review 31(4): 490-501.

Luna, Juan Pablo y David Altman. 2011. "Uprooted but Stable: Chilean Parties and the Concept of Party System Institutionalization". Latin American Politics and Society 53(2): $1-28$.

Luna, Juan Pablo y Cristóbal Rovira Kaltwasser. 2021. A la derecha de la derecha: ¿hay espacio para una fuerza populista radical de derecha? Montevideo: Fundación Friedrich Ebert.

Meléndez, Carlos y Cristóbal Rovira Kaltwasser. 2019. "Political Identities: The missing link in the Study of Populism". Party Politics 25(4): 520-533.

Morgan, Jana y Carlos Meléndez. 2016. "Parties under stress: using a linkage decay framework to analyse the Chilean party system". Journal of Politics in Latin America 8(3): 25-59.

Mudde, Cas. 2007. Populist Radical Right Parties. Cambridge: Cambridge University Press.

Mudde, Cas y Cristobal Rovira Kaltwasser. 2017. Populism: A Very Short Introduction. Oxford: Oxford University Press.

Mudde, Cas y Cristobal Rovira Kaltwasser. 2018. "Studying Populism in Comparative Perspective: Reflections on the Contemporary and Future Research Agenda". Comparative Political Studies 51(13): 1667-1693.

Palacios-Valladares, Indira. 2020. "Chile's 2019 October Protests and the Student Movement: Eventful Mobilization?" Revista de Ciencia Política 40(2): 215-234.

Peña, Carlos, 2020. Pensar el malestar: La crisis de octubre y la cuestión constitucional. Santiago: Taurus.

PNUD 2020. Diez años de la auditoría a la democracia. Antes del estallido. Santiago: Programa de las Naciones Unidas para el Desarrollo (PNUD).

Reyes-Housholder, Catherine y Beatriz Roque. 2019. “Chile 2018: Desafíos al poder de género desde la calle hasta La Moneda". Revista de Ciencia Política 39(2): 191-215.

Rhodes-Purdy, Matthew y Fernando Rosenblatt. 2021. "Raising the Red Flag: Democratic Elitism and the Protests in Chile". Perspectives on Politics (online first) http://doi. org/10.1017/S1537592721000050.

Rovira Kaltwasser, Cristóbal. 2019. “La (sobre)adaptación programática de la derecha chilena y la irrupción de la derecha populista radical". Colombia Internacional 99: 29-61.

Rovira Kaltwasser, Cristóbal. 2020. “El error de diagnóstico de la derecha chilena y su encrucijada actual". Revista de Estudios Públicos 158: 31-59.

Ruíz Encina, Carlos., 2020. Octubre chileno: La irrupción de un nuevo pueblo. Santiago: Taurus.

Sajuria, Javier. 2020, 29 de julio. "Rechazo: el Arcoíris que no fue". CIPER Chile. Recuperado el 13 de julio de 2021 de https:/ / www.ciperchile.cl/2020/07/29/rechazo-el-arcoirisque-no-fue.

Somma, Nicolás, Matías Bargsted, Rodolfo Disi Palic y Rodrigo Medel. 2020. “No water in the oasis: the Chilean Spring of 2019-2020". Social Movement Studies 20(4): 495-502. 
Stubager, Rune. 2010. The development of the education cleavage: Denmark as a critical case. West European Politics 33(3): 505-533.

Surridge, Paula, 2016. Education and liberalism: pursuing the link. Oxford Review of Education, 42(2): 146-164..

Tariq, Aamna, Eduardo Undurraga, Carla Castillo, Katia Vogt-Geisse, Richard Rothenberg y Gerardo Chowell, 2021. Transmission dynamics and control of COVID-19 in Chile, March-October, 2020. PLoS Negl Trop Dis 15(1): e0009070. https://doi.org/10.1371/ journal.pntd.0009070

Toro, Sergio y Macarena Valenzuela. 2020, 16 de julio. "¿Se desmorona el "cartel legislativo"? Grietas en un pilar del sistema político chileno". CIPER Chile.. Recuperado el 13 de julio de 2021 de https:/ /www.ciperchile.cl/2020/07/16/se-desmorona-el-cartel-legislativo-grietas-en-un-pilar-del-sistema-politico-chileno/

Vergara Perucich, Francisco, Ricardo Greene, Juan Correa Parra, Carlos Aguirre-Nuñez y Francisca Cancino Contreras. 2020. Cartografías del apruebo: Análisis preliminar del plebiscito para cambio constitucional, Chile 2020. 10.13140/RG.2.2.24281.34408.

Whitehead, Andrew, Samuel Perry y Joseph Baker. 2018. "Make America Christian Again: Christian Nationalism and Voting for Donald Trump in the 2016 Presidential Election". Sociology of Religion 79(2): 147-171.

Recibido: 5 de abril de 2021

Aceptado: 10 de julio de 2021

Carlos Meléndez es PhD en ciencia política, investigador asociado al Instituto de Investigación en Ciencias Sociales de la Universidad Diego Portales (ICSO-UDP) e investigador postdoctoral del Centro de Estudios de Conflicto y Cohesión Social (COES). Su principal área de investigación es la política comparada, específicamente identidades partidarias (positivas y negativas), sentimientos anti-establishment y vínculos políticos. Correo electrónico: carlos.melendez@mail.udp.cl

Cristóbal Rovira Kaltwasser es PhD en ciencia política, profesor titular de la Universidad Diego Portales (UDP) e investigador asociado del Centro de Estudios de Conflicto y Cohesión Social (COES). Su principal área de investigación es la política comparada y recientemente publicó junto a Tim Bale (Queen Mary University of London) el libro editado "Riding the Populist Wave: Europe's Mainstream Right in Crisis" (Cambridge University Press). Correo electrónico: cristobal.rovira@mail.udp.cl

Javier Sajuria es PhD es ciencia política, profesor asociado en la School of Politics and International Relations, Queen Mary University of London. Su área de trabajo es el comportamiento político comparado, en particular el análisis de élites y votantes. Recientemente se ha dedicado a estudiar la medición de la desinformación en términos comparados. Correo electrónico: j.sajuria@qmul.ac.uk 


\section{APÉNDICES}

Tabla A1: Modelo de regresión logística

\begin{tabular}{|c|c|}
\hline & Voto Rechazo \\
\hline \multirow[t]{2}{*}{ (Constante) } & $-5.90^{* * *}$ \\
\hline & $(1.20)$ \\
\hline \multirow[t]{2}{*}{ Izquierda-Derecha } & $0.46^{* * *}$ \\
\hline & $(0.06)$ \\
\hline \multirow[t]{2}{*}{ Conservador-Liberal } & $-0.16^{* * *}$ \\
\hline & $(0.05)$ \\
\hline \multirow[t]{2}{*}{ GSE } & 0.09 \\
\hline & $(0.14)$ \\
\hline \multirow[t]{2}{*}{ Mujer } & -0.53 \\
\hline & $(0.28)$ \\
\hline \multirow[t]{2}{*}{ Raza Blanca } & $0.56^{*}$ \\
\hline & $(0.28)$ \\
\hline \multirow[t]{2}{*}{ Tramo Etario } & 0.10 \\
\hline & $(0.11)$ \\
\hline \multirow[t]{2}{*}{ Educación Media } & 0.96 \\
\hline & $(0.50)$ \\
\hline \multirow[t]{2}{*}{ Educacion Universitaria } & $1.11^{*}$ \\
\hline & $(0.55)$ \\
\hline \multirow[t]{2}{*}{ Inmigración afecta el empleo } & $0.24^{*}$ \\
\hline & $(0.10)$ \\
\hline \multirow[t]{2}{*}{ Religión Católica } & 0.15 \\
\hline & $(0.34)$ \\
\hline \multirow[t]{2}{*}{ Religión Evangélica } & $0.93^{*}$ \\
\hline & $(0.39)$ \\
\hline AIC & 395.47 \\
\hline BIC & 450.12 \\
\hline Log Likelihood & -185.74 \\
\hline Deviance & 371.47 \\
\hline Num. obs. & 702 \\
\hline${ }^{* * *} \mathrm{p}<0.001,{ }^{* *} \mathrm{p}<0.01,{ }^{*} \mathrm{p}<0.05$ & \\
\hline
\end{tabular}


Tabla A2: Modelos multinomiales

\begin{tabular}{|c|c|c|}
\hline & Abstención & Rechazo \\
\hline \multirow[t]{2}{*}{ (Constante) } & $-4.15^{* * *}$ & $-5.85^{* * *}$ \\
\hline & $(1.05)$ & $(1.19)$ \\
\hline \multirow[t]{2}{*}{ Izquierda-Derecha } & $0.12^{*}$ & $0.46^{*+*}$ \\
\hline & $(0.06)$ & $(0.06)$ \\
\hline \multirow[t]{2}{*}{ Conservador-Liberal } & -0.06 & $-0.16^{* * *}$ \\
\hline & $(0.04)$ & $(0.05)$ \\
\hline \multirow[t]{2}{*}{ GSE } & 0.24 & 0.08 \\
\hline & $(0.13)$ & $(0.13)$ \\
\hline \multirow[t]{2}{*}{ Mujer } & -0.26 & -0.44 \\
\hline & $(0.26)$ & $(0.28)$ \\
\hline \multirow[t]{2}{*}{ Raza Blanca } & 0.02 & 0.54 \\
\hline & $(0.26)$ & $(0.28)$ \\
\hline \multirow[t]{2}{*}{ Tramo Etario } & 0.19 & 0.05 \\
\hline & $(0.11)$ & $(0.11)$ \\
\hline \multirow[t]{2}{*}{ Educación Media } & 0.41 & $0.97^{*}$ \\
\hline & $(0.40)$ & $(0.49)$ \\
\hline \multirow[t]{2}{*}{ Educacion Universitaria } & 0.62 & 1.04 \\
\hline & $(0.45)$ & $(0.54)$ \\
\hline \multirow[t]{2}{*}{ Inmigración afecta el empleo } & 0.05 & $0.24^{*}$ \\
\hline & $(0.09)$ & $(0.10)$ \\
\hline \multirow[t]{2}{*}{ Religión Católica } & 0.26 & 0.20 \\
\hline & $(0.30)$ & $(0.33)$ \\
\hline \multirow[t]{2}{*}{ Religión Evangélica } & 0.39 & $0.83^{*}$ \\
\hline & $(0.40)$ & $(0.39)$ \\
\hline AIC & 884.91 & 884.91 \\
\hline BIC & 996.54 & 996.54 \\
\hline Log Likelihood & -418.45 & -418.45 \\
\hline Deviance & 836.91 & 836.91 \\
\hline Num. obs. & 774 & 774 \\
\hline
\end{tabular}

